\title{
THE EFFECT OF DIET WATER CONTENT ON ENERGY EXPENDITURE BY THIRD-INSTAR MANDUCA SEXTA LARVAE (LEPIDOPTERA: SPHINGIDAE)
}

\author{
Heidi M. Van't HoF* and Michael M. Martin \\ Department of Biology, University of Michigan, Ann Arbor, MI 48109-1048, U.S.A.
}

(Received 17 May 1988; revised 24 November 1988)

\begin{abstract}
The total energy expenditure during the third instar of Manduca sexta larvae on a diet containing $65 \%$ water is substantially higher than that of larvae on a diet containing $82 \%$ water. The higher energy expenditure of larvae on the low-water diet is due to (1) a greater amount of time spent in the feeding stage of the instar and (2) to a higher respiration rate throughout the instar. We discuss problems in establishing causal links between diet, water content, growth and energy expenditure, and emphasize that the higher energy expenditure of larvae on a low-water diet is a consequence rather than a cause of reduced growth rate.
\end{abstract}

Key Word Index: Tobacco hornworm, Manduca sexta, water, respiration rates, metabolic costs, uric acid production

\section{INTRODUCTION}

Dietary water plays a critical role in the growth of herbivorous larval Lepidoptera (Mattson and Scriber, 1987; Slansky and Scriber, 1985). Consumption of food of low water content can result in significant reductions in relative growth rates and efficiencies of conversion of digested food (Scriber, 1977; Reese and Beck, 1978; Martin and Van't Hof, 1988; Schmidt and Reese, 1988; Timmins et al., 1988). Since growth requires the allocation of significant quantities of water for the hydration of newly synthesized tissue, water can be a growth-limiting nutrient for larvae on low-water diets (Schroeder, 1986; Martin and Van't Hof, 1988). In our earlier study (Martin and Van't Hof, 1988) we observed that 24-h-old, third-instar Manduca sexta larvae on an artificial diet containing $65 \%$ water respired at a significantly higher rate than larvae on a diet containing $82 \%$ water. We attributed this difference in respiration rate to the increased metabolic costs of processing the low-water diet, in particular to the excretion of surplus nitrogen in the form of uric acid and possibly also to the resorption of water from the hindgut. In the present study we have determined the effects of water content on the duration of the feeding and non-feeding stages of third-instar $M$. sexta larvae and on the respiration rates during each stage. In addition, we have measured the total amount of oxygen respired by larvae during the third-instar on high- and low-water diets, and have related entire instar oxygen consumption to the amount of assimilated food allocated to energy metabolism.

\section{MATERIALS AND METHODS}

Insects

Tobacco hornworms, $M$. sexta (Lepidoptera: Sphingidae), were reared from eggs (Carolina Bio-

*To whom all correspondence should be addressed. logical Supply) to the third-instar on an artificial diet (Bio-Serv No. 9783) containing $82 \%$ water at $24^{\circ} \mathrm{C}$, under $16 \mathrm{~h}$ light $-8 \mathrm{~h}$ dark.

\section{Duration of feeding and non-feeding stages}

To determine the duration of the feeding and non-feeding stages, newly moulted third-instar larvae were weighed and placed singly into $50 \times 9 \mathrm{~mm}$ plastic Petri dishes containing a cube of diet of 82 or $65 \%$ water on a toothpick. After $48 \mathrm{~h}$, larvae were weighed every $2-3 \mathrm{~h}$ until they moulted to the fourthinstar. The end of the feeding stage was taken to be the first time at which larval mass decreased.

\section{Respiration}

To measure respiration rates throughout the instar, four newly moulted third-instar larvae were weighed and placed singly in 12- or 22-ml respirometer flasks which were attached to a Gilson respirometer (Model No. GR 14). Each flask contained $0.4 \mathrm{ml}$ of $10 \%$ potassium hydroxide in the centre well, approx. $200 \mathrm{mg}$ of artificial diet with a water content of either 82 or $65 \%$ placed on a toothpick outside the centre well, and $0.5 \mathrm{ml}$ of distilled water in the sidearm. Larvae were sedentary on the toothpicks. Following a 30-min equilibration period, oxygen consumption was measured at $25^{\circ} \mathrm{C}$. During the first $12 \mathrm{~h}$ of the instar, respiration was measured during three consecutive $4-h$ periods. For hours $13-25$ of the instar, respiration was measured during consecutive 2- to 3-h periods. For hours 26-37, respiration was measured for 1-h periods approximately every $5 \mathrm{~h}$. For the remainder of the instar, respiration was measured for $1-\mathrm{h}$ periods every $2-3 \mathrm{~h}$. Larvae and faeces were removed from the flask and weighed at hours 12 and 23 , and approximately every $5 \mathrm{~h}$ thereafter. One hour was required to weigh larvae and faeces and reequilibrate the flasks in the water bath. The artificial diet and potassium hydroxide solution were replaced every $8-10 \mathrm{~h}$. The barometric 
pressure was recorded for each measurement period and respiration rates were calculated at STP. Initial and final larval wet mass were averaged to provide a mean larval wet mass for each measurement period. The end of the feeding stage was taken to be the first time at which larval mass decreased. To estimate the cumulative amount of oxygen respired during the instar, the amount of oxygen respired during the actual measurement intervals was added to the calculated amount respired during the intervals between measurements, assuming values for larval mass and respiration rate halfway between the values determined during the measurement periods immediately preceding and following the non-measured interval.

Respiration rates were also measured on large numbers of larvae in the feeding stage (10 and $30 \mathrm{~h}$ after the moult) and in the non-feeding pre-moult stage $(60 \mathrm{~h}$ after the moult for larvae on the highwater diet and $80 \mathrm{~h}$ after the moult for larvae on the low-water diet). Respiration rates during ecdysis were also measured for a small number of larvae. Respiration was measured for $30 \mathrm{~min}$ following a $15-\mathrm{min}$ incubation period in flasks prepared as described above. Respiration rates on each diet, expressed as $\mu \mathrm{l} / \mathrm{O}_{2} / \mathrm{h}$ per mg (wet mass) of larva, were compared by Mann-Whitney U-tests.

\section{Uric acid determination}

The uric acid content of faeces egested during measurements of respiration in the feeding stage was determined by the procedure of Martin and Van't Hof (1988). Since the total amount of faeces produced was small, it was necessary to carry out the uric acid analysis on a single extract prepared from a pooled sample of faeces from all individuals on each diet at each time interval. The uric acid content of larvae was also determined. Two uric acid extractions were made from defatted larval tissue pooled from all individuals on each diet in the feeding and nonfeeding stages. Assays for uric acid content of all extracts were conducted in duplicate.

\section{RESULTS}

The third-larval instar of $M$. sexta can be divided into three distinct stages, a feeding stage during which growth occurs, a non-feeding pre-moult stage during which there is no further growth, and an ecdysis stage (Table 1). A low-water diet significantly prolongs the feeding stage of third-instar $M$. sexta. Larvae on the low-water diet spend 16 more hours in the feeding stage than larvae on the high-water diet. Because the non-feeding stage is unaffected, larvae on the lowwater diet require 16 more hours to complete the third instar than larvae on the high-water diet.

A low-water diet also significantly increases the rate of larval respiration (Table 2). Larvae on the low-water diet respire at a rate $41-52 \%$ higher than larvae on the high-water diet in the feeding stage (10 and $30 \mathrm{~h}$ after the moult), the non-feeding stage (60 and $80 \mathrm{~h}$ after the moult for larvae on the high-water and the low-water diet, respectively) and the ecdysis stage of the third instar. Two processes likely to contribute to the greater expenditure of energy by the larvae on the low-water diet are the synthesis and
Table 1. Duration (h, mean and SE) of the feeding stage, the non-feeding stage and the entire third instar of $M$. sexta larvae feeding on artificial diets of high or low water content

\begin{tabular}{lccc}
\hline & \multicolumn{2}{c}{ Duration $(\mathrm{h})$} & \\
\cline { 2 - 3 } Larval stage & High-water diet & Low-water diet & $P$ value \\
\hline Feeding & $46.0 \pm 0.29$ & $62.2 \pm 2.15$ & 0.0001 \\
Non-feeding & $20.8 \pm 0.55$ & $21.2 \pm 0.27$ & 0.1410 \\
Entire instar & $66.8 \pm 0.58$ & $83.3 \pm 2.23$ & 0.0001 \\
\hline
\end{tabular}

The number of larvae was 19 and 20 for the high-water and low-water diets, respectively. Significance values are given for Mann-Whitney U-tests.

excretion of larger quantities of uric acid and the resorption of larger amounts of water from the contents of the rectum, both of which were documented in our earlier study (Martin and Van't Hof, 1988).

In this study we have examined the time course of uric acid production (Table 3). At $10 \mathrm{~h}$ after the moult, the uric acid content of larvae and the faeces they produce on the low-water diet was no higher than that of larvae and faeces on the high-water diet. By $30 \mathrm{~h}$ after the moult, however, the faeces produced by larvae on the low-water diet contained nearly four times as much uric acid as the faces of the larvae on the high-water diet. There was no difference in larval uric acid content at $30 \mathrm{~h}$ after the moult. By the non-feeding stage, the larvae on the low-water diet

Table 2. Respiration rate ( $\mu \mathrm{l} \mathrm{O}_{2} / \mathrm{h} / \mathrm{mg}$ wet mass at STP) (mean and SE) of third-instar $M$, sexta larvae feeding on artificial diets of high or low water content in the feeding stage $(10-\mathrm{h}$ and 30 -h after the moult), the non-feeding stage ( $60 \mathrm{~h}$ after the moult for larvae on the high-water diet and $80 \mathrm{~h}$ after the moult for larvae on the low-water diet) and during ecdysis to the fourth-instar

\begin{tabular}{cccc}
\hline Larval stage & High-water diet & Low-water diet & $P$ value \\
\hline $\begin{array}{ccc}\text { Feeding stage } \\
10 \text {-h }\end{array}$ & $1.38 \pm 0.048$ & $1.94 \pm 0.041$ & 0.0001 \\
& $(37)$ & $(42)$ & \\
$30-h$ & $1.29 \pm 0.027$ & $1.96 \pm 0.029$ & 0.0001 \\
& $(40)$ & $(43)$ & \\
Non-feeding & $0.53 \pm 0.018$ & $0.77 \pm 0.027$ & 0.0001 \\
stage & $(56)$ & $(46)$ & \\
Ecdysis & $0.85 \pm 0.053$ & $1.24 \pm 0.008$ & 0.0100 \\
& $(4)$ & $(6)$ & \\
\hline
\end{tabular}

Significance levels are given for Mann-Whitney U-tests, and the sample sizes are provided in parentheses.

Table 3. Uric acid content ( $\% \mathrm{wt} / \mathrm{wt}$ ) of faeces and $M$. sexta larvae on artificial diets of high or low water content during the feeding ( 10 and $30 \mathrm{~h}$ following the moult to the third-instar) and non-feeding $(60 \mathrm{~h}$ after the moult for larvae on the high-water diet and $80 \mathrm{~h}$ after the moult for larvae on the low-water diet) stages of the third-instar

\begin{tabular}{lcc}
\hline Larval stage & High-water diet & Low-water diet \\
\hline $\begin{array}{c}\text { Feeding stage } \\
\text { 10-h }\end{array}$ & & \\
Faeces & 0.324 & 0.332 \\
Larvae & 1.088 & 1.168 \\
30-h & $(1.080-1.096)$ & $(1.168-1.232)$ \\
Faeces & 0.288 & 1.131 \\
Larvae & 1.470 & 1.557 \\
Non-feeding stage & $(1.432-1.508)$ & $(1.551-1.563)$ \\
Larvae & 1.594 & 2.489 \\
& $(1.445-1.742)$ & $(2.267-2.711)$ \\
\hline
\end{tabular}

Values for larvae are means with the range of two determinations provided in parentheses. Values for faeces are from single determinations. 


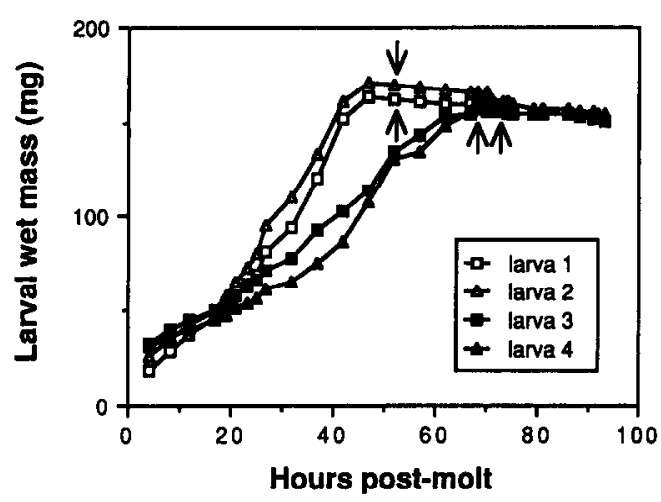

Fig. 1. Wet mass (mg) of third-instar $M$. sexta larvae feeding on high-water (larva 1 and 2, open symbols) or low-water (larva 3 and 4 , solid symbols) artificial diets. Arrows indicate the end of the feeding stage.

had accumulated $56 \%$ more uric acid than the larvae on the high-water diet. Thus, the synthesis and excretion of uric acid is clearly one process that accounts for the higher energy expenditure of the larvae on the low-water food, especially during the non-feeding pre-moult phase and the second half of the feeding phase.

The changes in larval mass and respiration rate over the entire instar are illustrated for two larvae on each diet in Figs 1 and 2. The feeding stages of larvae 1 and 2 lasted $52 \mathrm{~h}$ while the feeding stages of larvae 3 and 4 lasted 70 and $71 \mathrm{~h}$, respectively (Fig. 1). The non-feeding stages for larvae $1-4$ lasted $20,19,22$ and $22 \mathrm{~h}$, respectively. These measurements are consistent with the results reported in Table 1 , showing that diet-water content affects the duration of the feeding stage but not the non-feeding stage. It is clear from Fig. 2 that larval respiration rates are much higher during the feeding stage than during the non-feeding and ecdysis stages. Within the first half of the feeding stage respiration rates are consistently high, but they decline slowly in the second half as the rates of food consumption and growth slow. Within the nonfeeding and ecdysis stages, respiration rates are consistently low with a modest increase in respiration rate during the moult to the fourth instar. Inspection of Fig. 2 also reveals that the respiration rates of larvae on the low-water diet (larvae 3 and 4) are

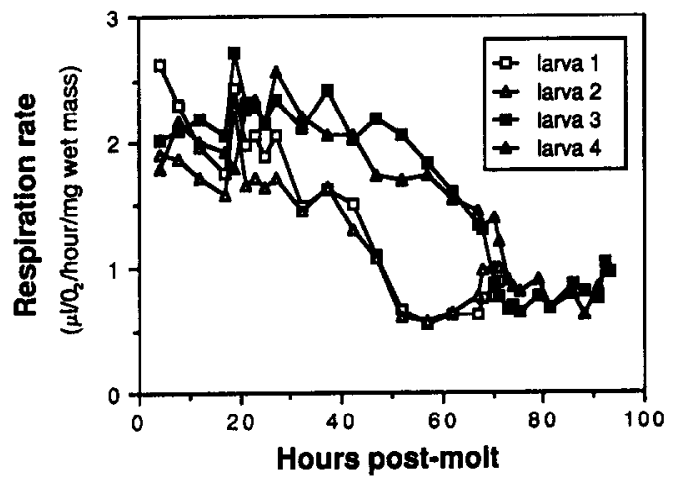

Fig. 2. Respiration rates $\left(\mu 1 \mathrm{O}_{2} / \mathrm{h} / \mathrm{mg}\right.$ wet mass at STP) of third-instar $M$. sexta larvae feeding on high-water (larva 1 and 2, open symbols) or low-water (larva 3 and 4, solid symbols) artificial diets. Arrows indicate the end of the feeding stage.
Table 4. Energy expenditure of $M$. sexta larvae feeding on artificial diets of high or low water content during the third-instar. Values for total oxygen respired were calculated from the respirometry data used to construct Fig. 2 (see Materials and Methods)

\begin{tabular}{lccc}
\hline & \multicolumn{2}{c}{ Diet } & \\
\cline { 2 - 3 } Parameter & High-water & Low-water & Increase \\
\hline $\begin{array}{l}\text { Oxygen respired } \\
\text { ( } \mu \text { 1/larvae/instar) }\end{array}$ & $8.95 \times 10^{3}$ & $14.80 \times 10^{3}$ & $65.4 \%$ \\
$\begin{array}{l}\text { Assimilated dry mass } \\
\text { not used for growth } \\
\text { (mg/larva/instar) }\end{array}$ & $12.39 \pm 0.496$ & $20.22 \pm 0.701$ & $63.1 \%$ \\
$\begin{array}{l}\text { Gravimetric values (mean and SE) are from data reported in Martin } \\
\text { and Van't Hof (1988), and the sample size is indicated in } \\
\text { parentheses. }\end{array}$ & $(33)$ & $(36)$ &
\end{tabular}

higher than the respiration rates of larvae on the high-water diet (larvae 1 and 2) in both the feeding and non-feeding stages, consistent with the more extensive measurements reported in Table 2. From the data used to construct Fig. 2, it is possible to calculate the total amount of oxygen respired during the third instar by larvae on each diet. The total amount of oxygen consumed by larvae on the lowwater diet is $65.4 \%$ higher than the amount respired by the larvae on the high-water diet (Table 4). This value is in striking agreement with the $63.1 \%$ increase in the amount of dry matter allocated to energy metabolism.

\section{DISCUSSION}

Earlier studies have demonstrated that diet water content has a significant effect on the growth rates of herbivorous caterpillars (Scriber, 1977; Reese and Beck, 1978; Schmidt and Reese, 1988; Timmins et al., 1988; Martin and Van't Hof, 1988). In this study we have shown that diet water content has a significant effect on energy metabolism. We have shown that the energy expended by $M$. sexta larvae during the third instar is higher on the low-water diet for two reasons: (1) because the instar is longer, and (2) because the respiration rate during each stage of the instar is higher.

It is very easy to confuse cause and effect in interpretations of the relationship between growth rate and metabolic rate (Martin and Van't Hof, 1988). Although lower growth rates on a particular food are frequently attributed to higher metabolic costs associated with processing that food, we believe that a reduced growth rate is more often the cause rather than the consequence of a higher expenditure of energy. This point is well illustrated by the relationship between diet water content, growth rate, and metabolic rate in $M$. sexta. On a diet containing $65 \%$ water, the larvae grow more slowly, respire more rapidly, and expend a greater total amount of energy during the third instar than larvae on a diet containing $82 \%$ water. On the low-water diet, water is the growth-limiting nutrient, whereas on the highwater diet it is not. As a consequence, larvae on the low-water diet must excrete surplus assimilated nutrients, such as nitrogen, by endergonic processes that result in an increase in metabolic rate. The reduced growth rate prolongs the feeding stage, the stage of the instar associated with the highest metabolic rate, thereby mandating a greater total expenditure of energy during the instar. Thus, high energy costs of 
food processing are not the cause of reduced rates of growth of $M$. sexta larvae on a low-water diet, but rather the consequence of slower growth imposed by nutrient limitation.

Acknowledgement-We thank the National Science Foundation for a grant (BSR-8421268) to M.M.M., which supported this research.

\section{REFERENCES}

Martin M. M. and Van't Hof H. M. (1988) The cause of reduced growth of Manduca sexta larvae on a low-water diet: increased metabolic processing costs or nutrient limitation? J. Insect Physiol. 34, 515-525.

Mattson W. J. and Scriber J. M. (1987) Nutritional ecology of insect folivores of woody plants: nitrogen, water, fiber and mineral considerations. In Nutritional Ecology of Insects, Mites, Spiders, and Related Invertebrates (Edited by Slansky Jr F. and Rodriguez J. G.), pp. 105-146. Wiley, New York.

Reese J. C. and Beck S. D. (1978) Inter-relationships of nutritional indices and dietary moisture in the black cutworm (Agrotis ipsilon) digestive efficiency. J. Insect Physiol. 24, 473-479.

Schmidt D. J. and Reese J. C. (1988) The effects of physiological stress on black cutworm (Agrotis ipsilon) larval growth and food utilization. J. Insect Physiol. 34, 5-10.

Schroeder L. A. (1986) Protein limitation of a tree leaf feeding Lepidopteran. Ent. exp. appl. 41, 115-120.

Scriber J. M. (1977) Limiting effects of low leaf water content on the nitrogen utilization, energy budget and larval growth of Hyalophora cecropia (Lepidoptera: Saturniidae). Oecologia 28, 269-287.

Slansky F. Jr and Scriber J. M. (1985) Food consumption and utilization. In Comparative Insect Physiology, Biochemistry and Pharmacology (Edited by Kerkut G. A. and Gilbert L. I.), Vol. 4, pp. 87-163. Pergamon Press, Oxford.

Timmins W. A., Bellward K., Stamp A. J. and Reynolds S. E. (1988) Food intake, conversion efficiency, and feeding behavior of tobacco hornworm caterpillars given artificial diet of varying nutrient and water content. Physiol. Ent. 13, 303-314. 